\title{
Preparing pre-service teachers for multilingual classrooms - designing a multiple African language module
}

\begin{abstract}
A B S T R A C T South African classrooms have become increasingly diverse and the shifting demographics of the instructional context have necessitated a change in the way preservice students are prepared for the linguistic and cultural diversity of their future classrooms. In response to this, undergraduates enrolled in the Faculty of Education at the University of Pretoria are now required to extend their personal language repertoire by acquiring a functional knowledge of words and appropriate phrases for instructional purposes in an African language (Afrikaans, Northern Sotho, Tswana or Zulu). A particular innovation of this new credit-bearing module has been the creation of a multimedia CD with visual and audio course content (read by native speakers). The module also offers a historical overview of the linguistic diversity encountered in especially urban classrooms as well as an appreciation of diversity in the pedagogical context. This article addresses the challenge and process of the curriculum design using the classic ADDIE model. It also documents student reaction to the compulsory module as well as their experience of language learning.
\end{abstract}

Key words: curriculum + multilingual classrooms, instructional design and development, language learning, multilingualism.

\section{Introduction}

In recent decades, school populations - especially in industrialised countries - have rapidly been changing as globalisation and inter-continental migration enrich the classroom composition in terms of cultural and linguistic variables (Farr, Seloni and Song, 2010). In South Africa, political changes since 1994 have further amplified this increase in classroom diversity. The gradual deracialisation of schools and the concomitant shifting demographics 
have necessitated a change in the way pre-service educators are prepared for the diversity of the current South African classroom.

Currently pre-service teachers' internship placements as well as their eventual employment commonly take place in linguistically and culturally diverse schools. They thus need to communicate with colleagues and learners or their caregivers from different communities. Having even a basic vocabulary in another language demonstrates goodwill and facilitates understanding. Teachers in post-apartheid classrooms - especially in urban areas - are also often faced with the challenge of facilitating learning using a language not spoken by learners at home, and at times, one they themselves lack confidence in using (Evans and Cleghorn, 2010). This is problematic especially at lower grade levels when learners must acquire the language of learning, teaching and assessment (LoLTA) as an additional language. Knowledge of appropriate phrases in another language ought to not only make student teachers feel more confident about communicating with learners whose mother tongue differs from theirs but should also help facilitate classroom routine (Evans et al., 2009).

In recent months, the Higher Education ministry has proposed - as a special ministerial project - the development and teaching of African languages in universities. Also being mooted is that every university student in South Africa could be required to learn one African language as a prerequisite for graduating (Masombuka, 2011). This move may require all tertiary institutions to consider designing appropriate interventions. In 2006, in what now seems to have been a pro-active move by a visionary dean, the Faculty of Education at the University of Pretoria introduced a credit-bearing core module strongly underpinned by the exposure to an African language. Furthermore, the module aims to engender a respect for one's own as well as others' languages and thus endorses the additive approach to language development required by the language policy of the Department of Education, (Department of Education, 2003). The purpose of this article is to describe the challenges and processes of designing and operationalising a module which better equips student teachers to deal with the linguistic diversity prevalent in most South African classrooms. This description may provide some direction to other practitioners facing similar future endeavours. After an explanation of the contextual challenges, the five distinct phases of the instructional design process have been explained. The module outcomes and course outline have also been provided. Quantitative and qualitative data have been integrated where appropriate. An overview of the second phase of curriculum development as well as students' reaction to the course content and by implication, to their introductory experience of learning a new language, conclude the narrative.

\section{Challenges}

The introduction of a new module was originally an imperative from the dean's office in sharp reaction to another module which was deemed to run "contrary to the basic commitments of curriculum transformation" (Jansen, 2009:176). It was to be replaced by one which would provide a less biased and stereotypical introduction to multiculturalism and would rather emphasise the multilingual facet of diversity.

Course content was shaped by several logistical challenges viz. large groups, limited contact time, few resources, and multiple role players - the most palpable one being class size. When teaching or learning a new language, it is ideal to work with few learners placed in small 
groups as this ensures high levels of participation and quality engagement. Large groups militate against effective facilitation of language acquisition and remain challenging with regard to keeping students on task. A cursory electronic search using "optimal class size + language learning" as key terms, spawned thousands of sites from across the globe posted by various researchers, professional bodies and leading language teaching organisations. The earliest research-based suggestion is ten learners "under intensive conditions" (Horne, 1970:1) while the general consensus is that the class size should not exceed fifteen learners (Krieger, 2003; Morgan, 2000; Nan, 2005). In our case, the annual intake of well over 700 students thus presented a particular pedagogical challenge.

The challenge of class size was compounded by the goal of offering four languages simultaneously for which highly proficient speakers of the target language, who also had language teaching experience, were required. Initial planning revealed that 13-15 African language specialists (1 per 55 students) proficient enough to teach multiple groups in both English and Afrikaans 1 would need to be sourced. This had particularly problematic financial and human resource implications. Furthermore, having only seven contact sessions i.e. 7 x 50 minutes (less than 6 hours) in which to equip prospective teachers with strategies for dealing more effectively with multilingualism in a culturally diverse pedagogical context, called for a careful selection and structuring of content.

The assessment of expressive communicative skills remains a challenge in language teaching. Not only is this type of assessment more subjective than, say, testing grammatical competence, but the number of students presented a further logistical challenge. The original intention had been for students to take a final oral examination but again practicalities such as class size, time, and money overruled idealism ${ }^{2}$.

Aside from the instructional challenge of preparing a blending learning mode with audiolingual echoes, the primary logistical challenge thus faced was the labour-intensive task of teaching and assessing an entire year group with limited contact time, and the necessity of specialist lecturers.

\section{Curriculation process}

Bearing these challenges in mind, the new module took shape as a team of language and instructional design specialists implemented the ADDIE model (Analyse, Design, Develop, Implement, and Evaluate) as framework. This model was originally designed in 1975 for military training purposes (Watson, 1981) and its five phases offer a means of analysing students' needs, designing and developing content and materials, implementing and finally evaluating the efficacy of the instructional intervention. This model in its broad sense - as set out below - guided the curriculation process.

1 University policy dictates that the language of teaching and learning at undergraduate level is either English or Afrikaans unless otherwise specified.

2 One session of four students per half-hour equalled more than 80 hours for an average group of 650 students. This breaks down to roughly 25 hours per African language instructor - almost a full working week, if preparation time and essential admin./body breaks are included. An external moderator per language would also need to have been factored in - resulting in a very high price literally and figuratively. 


\section{Analyse}

Change in any form generally elicits some negative perceptions and in South Africa, language matters have always been emotionally charged. An initial focus group and informal corridor conversations with students about the proposed module triggered an alert to possible resistance to learning a language as a compulsory component of the B Ed programme. Some students questioned the necessity of extending their language profile; others were reluctant to study another language.

An initial analysis was done of the context in which prospective teachers would be working. Observations of and discussions with teachers in situ suggested some diversity themes to address. Student interns were asked to collect a list of frequently used words and phrases which helped categorise the types of teacher talk used. Admittedly this was not a rigorously scientific process and with the view to refining the module, the consultation of corpora to determine the validity of what is perceived to be high frequency vocabulary ought to be considered. In this regard, Schmitt (2010) offers useful advice about selecting lexical units although with the view to facilitating reading comprehension.

An analysis to determine the target audience profile, their needs, expectations and existing competencies, helped sharpen design focus. Statistics gleaned from official records were borne out by the electronic surveys conducted between 2006 and 2011 and continue to inform the iterative process of course development. The latter data indicate that $61.2 \%$ of the cohort are 21 years while $8.8 \%$ are 24 years or older. Female students make up $77.6 \%$ of the group mirroring the national demographics of the teaching profession. With regard to the language which students feel they speak best, $53.7 \%$ are Afrikaans-speaking while 25.1\% claim English as a mother tongue. This reflects a downward shift from 57.7\% Afrikaans speakers in 2007 and matches the changing demography of the campus. Northern Sotho is spoken by $7.2 \%$ of students which is an accurate reflection of the South African geo-linguistic map in terms of the university's location. The only other language that has a significant representation is Swati (5.8\%). Other non-official languages spoken at home by students include Cantonese, Dutch, German, Korean, Marathi, and Portuguese. While there is miniscule representation from each of the nine provinces in South Africa, 3\% of the students live outside the national borders suggesting that they may never have had exposure to the languages the module offers. The majority (80.8\%) live within the traditional feeder area of the university: Gauteng (55.3\%), Mpumalanga (18.9\%) and, Limpopo (6.6\%). This tallies with the regional distribution of the languages spoken by the undergraduates. Annually 35\% of the students intend teaching in the Foundation phase, while 50\% will apply for appointments in the Further Education and Training (FET) band. 72.6\% of the students passed English as a second language on the higher grade level in Grade 12. Having formed a clear idea for whom we were preparing the module and the linguistic demands they would face in multilingual classrooms, it was possible to start designing a relevant curriculum.

\section{Design}

Dick and Carey's refinement of the ADDIE model (2000) and constructive alignment as coined by Biggs (1996) underpinned the instructional design process. Given the limited face-to-face 
contact, much self-study and peer practise would be required for students' to internalise the content. Biggs' premise suggests that for learning to be effective, it ought to be regarded "in qualitative not quantitative terms" (1996:348) and that a close match is evident in learning tasks, assessments and course outcomes. All teaching and learning activities are crafted to foster deep learning and the learner is required to be actively engaged in constructing meaning for themselves. Once a framework had been plotted and operational logistics anticipated, the course content was planned.

The work of applied linguists such as Nation (2001), Thornbury (2002), Bogaards and LauferDvorkin (2004), and Nan (2005) were consulted for vocabulary teaching strategies. Drawing on organisational theorists and workplace diversity theories (De Beer and De Beer, 2009; Pettigrew, 2008; Hayles and Russel, 1997) the module was also designed to sensitise prospective teachers to the richness which the current educational context offers and to enable them to create an instructional climate that values and respects difference and is conducive to learning. The module outcomes dovetail well with the recently gazetted basic competences expected of a beginner teacher which require, among others, an understanding of diversity and a teaching style which includes all learners and supports learning (Department of Basic Education, 2011:53). Thematically there is also a strong link with foundational knowledge contained in modules comprising the core Education suite.

The final product, Classroom Literacies, was registered as a compulsory 7 -week module bearing three credits and it consists of four units designed to enrich students' personal language profile. Students are expected to acquire a functional knowledge of words and instructional phrases in one of four national languages (Afrikaans, Northern Sotho, Tswana or Zulu ${ }^{3}$ ). They are required to choose an indigenous language in which they have no competence. By implication they cannot take a language passed at Grade 12 level, regardless of status (home or additional language) or taken at university. Upon completion of this module, students need to show evidence of having

- grasped the pedagogical issues related to teaching and learning in an additional language context;

- gained respect and appreciation for a diverse pedagogical context;

- enriched their understanding of how linguistically diverse South African classrooms are, and how this language diversity came about;

- broadened their knowledge of and respect for other's cultural habits;

- recognised and acquired an accurate pronunciation of \pm 200 words and phrases frequently used for instructional purposes relating to social and familial exchanges, learners and learning environment, behaviour management, and phatic or affective communication, and

- improved their information search skills using electronic dictionaries, translation and pronunciation guides.

The detailed course outline finally approved is provided in Table 1.

3 These are languages for which lecturers were readily available. 
Table 1: Teaching and learning plan (a blended learning approach ${ }^{4}$ ) for JKL251 Classroom Literacies

\begin{tabular}{|c|c|c|}
\hline Outcomes & $\begin{array}{l}\text { Learning facilitation activities } \\
\text { (blended approach) }\end{array}$ & $\begin{array}{l}\text { Assessment } \\
\text { (blended approach) }\end{array}$ \\
\hline $\begin{array}{l}\text { UNIT } 1 \\
\text { Linguistic diversity in } \\
\text { South African classrooms } \\
\text { After studying the content, you } \\
\text { should be able to... } \\
\text { - contextualize the languages of } \\
\text { South Africa within the broader } \\
\text { perspective of the languages of } \\
\text { Africa. } \\
\text { - describe the language diversity } \\
\text { in the South African classroom. } \\
\text { - explain the relationship between } \\
\text { the different South African } \\
\text { Bantu languages. } \\
\text { - list the reasons for the } \\
\text { multilingual nature of the South } \\
\text { African society. } \\
\text { - explain why a monolingual } \\
\text { language policy will not be in } \\
\text { the interests of the citizens of } \\
\text { South Africa. } \\
\text { - compile your own language } \\
\text { profile and identify its strengths } \\
\text { and weaknesses. }\end{array}$ & $\begin{array}{l}\text { Students will ... } \\
\text { - study the glossary in order to } \\
\text { complete crossword } \\
\text { - complete a web quest related } \\
\text { to multilingualism as a global } \\
\text { phenomenon } \\
\text { - interpret a linguistic map of } \\
\text { South Africa } \\
\text { - read a scenario and discuss } \\
\text { prompt questions on-line in } \\
\text { groups of } 10 \\
\text { - draft their personal language } \\
\text { profile }\end{array}$ & $\begin{array}{l}\text { - Submit crossword } \\
\text { - Complete E-quiz } \\
\text { - Write CBT (knowledge based) } \\
\text { - Submit research paper based on } \\
\text { web quest } \\
\text { - Interact on prescribed topic } \\
\text { using discussion tool/chat room } \\
\text { - Submit personal language profile } \\
\text { - Knowledge and understanding of } \\
\text { this theme will be evidenced in } \\
\text { reflective essay }\end{array}$ \\
\hline $\begin{array}{l}\text { UNIT } 2 \\
\text { Understanding cultural practices } \\
\text { and social spaces } \\
\text { After studying the content, you } \\
\text { should be able to... } \\
\text { - describe the three symbolic } \\
\text { spaces in which we interact daily } \\
\text { and explain how social prejudice } \\
\text { ought to be dealt with. } \\
\text { - explain the convention of } \\
\text { naming and greeting in various } \\
\text { communities. } \\
\text { - describe aspects of non-verbal } \\
\text { communication which manifest } \\
\text { in a culture other than your own. } \\
\text { - describe forms of celebration } \\
\text { found in a community other } \\
\text { than your own. } \\
\text { - explain reasons why learners } \\
\text { may be absent from school. } \\
\text { - promote an appreciation and } \\
\text { mutual respect among learners } \\
\text { for the cultural diversity which } \\
\text { enriches the classroom. }\end{array}$ & $\begin{array}{l}\text { Students will ... } \\
\text { - study the glossary } \\
\text { - interview } 3 \text { peers regarding their } \\
\text { names, customs, beliefs and } \\
\text { habits. } \\
\text { - Complete a self-knowledge } \\
\text { checklist } \\
\text { - Take part in on-line discussion } \\
\text { in which students share opinions } \\
\text { on and examples of cultural } \\
\text { diversity. Prompt questions } \\
\text { posted by lecturer }\end{array}$ & $\begin{array}{l}\text { - Complete a computer-based test } \\
\text { (CBT) (content/theory based) } \\
\text { - Complete a table post-interview } \\
\text { - Peer-discuss checklist } \\
\text { - Grade participation in discussion }\end{array}$ \\
\hline
\end{tabular}




\section{UNIT 3}

Lexicographical literacy

After studying the content, you

should be able to...

- distinguish between basic types of print and on-line dictionaries, pronunciation and translation guides.

- select an appropriate dictionary for your own use as well for your learners' needs.

- identify and label the different components of a dictionary entry.

- look up words or terms in various types of dictionaries.

- illustrate differences between using a dictionary for understanding meaning or for writing and speaking.

\section{UNIT 4}

Language specific content covering basic words and phrases frequently used in a pedagogical context e.g. Zulu

After studying the content, you should be able to...

- recognise and pronounce correctly at least 200 Zulu words, phrases, constructions and sentences found in this unit.

- initiate and respond to basic social exchanges such as greetings, asking basic questions and giving elementary instructions in Zulu.

- explain the most important ways in which the structure of Zulu differs from that of your mother tongue.

- reflect on how you would apply what you have learnt in this unit in a multilingual classroom situation.
Students will ...

- study the glossary

- answer simple questions relating to dictionary use and lexicography based on an information search

- access an on-line dictionary and complete a questionnaire (part of web quest)

- consult a visual thesaurus and replicate the spider map
- Complete E-quiz

- Write CBT (content based)

- Grade questionnaire \& spider map as part of web quest submission
Students will ...

- study the glossary

- study the word and phrase lists in conjunction with the multimedia CD.

- practise pronunciation using the hard copy and audio guide as well as pair work

- label objects in a visual

- representation of a typical classroom

- participate in an on-line discussion in which they respond to questions relating to language specific features

- listen to audio clips and correctly identify the instructions or greetings

- complete traditional language exercises in order to practise giving instructions or making requests
- Write a CBT exam ${ }^{5}$ in

- which nouns, verbs, instructions, greetings, colour, time, numbers, shapes and proverbs are tested using a variety of visual and audio clips.

- On-line discussion.

- Submission of reflective essay

- Completion of on-line survey

4 Tasks do not necessarily run sequentially but are often combined across units.

5 Students enrolled for Afrikaans are usually no more than 20 students. They are tested orally as is the ideal in language teaching and learning. 


\section{Develop}

The entire curriculation project, including a pilot segment, was executed in fifteen months, assisted by specialists from the Departments of African Languages and Education Innovation. The development phase pertained to the preparation of tangible products i.e. study guides, a textbook, an electronic classroom management system which offers further academic and administrative support, multiple choice test items and a multi-media $\mathrm{CD}$, the latter being the primary learning support tool providing both visual and aural stimuli. Seed funding was obtained for the development of the CD which was externally evaluated in 2008. Captured in accessible electronic format and recorded by native speakers ${ }^{6}$, is a language-specific pronunciation audio guide as well as the bank of words and phrases in four languages. A rendition of a traditional song and the national anthem by a children's choir has been included for future teaching purposes. The fact that four widely used official languages have been recorded extends the CD's usefulness as graduates may well take up appointments in regions where a language other than the one they enrolled for is spoken.

As an alternative to an oral examination, the same audio clips as recorded on the CD were used to compile an electronic item bank from which to draw computer-based tests (CBTs). Colleagues helped to formulate and translate more than 500 multiple choice questions (see Addendum A) based on the generic historic and cultural subject knowledge to be mastered as well as vocabulary and phrases from the four specific languages on offer. Questions test a range of cognitive skills and students cannot merely rely on rote learning - a close resemblance to an assessor asking students to identify or match the words/phrases verbally. Other assessment modes include a peer interview and mini-research tasks as well as a reflective essay submitted as a pre-requisite for examination entrance.

During this phase, two unexpected situations arose suggesting how closely and emotionally one's identity is linked to one's mother tongue. Several persons who had nothing to do with academia e.g. visitors, cleaners and delivery staff became very interested in the project and offered advice or comments on aspects of their mother tongue as the $\mathrm{CD}$ was being processed by the instructional designers. The second was strong disagreement between native speakers and the language specialists arguing about usage (lexicon, idiomatic expressions, pronunciation, or orthography). The academic opinion finally prevailed with what was commonly considered to be the standard variety. Native speakers gained new insights into the nuances and variations of their mother tongue.

\section{Implement}

A month prior to the commencement of the first contact sessions in late 2006, an information session was offered on different days in English and Afrikaans. Here the rationale for and aim of the new module was presented while logistics and some administrative matters, were discussed. Advice was given on which language to choose and questions/suggestions were processed. Final

6 It is acknowledged that several regional varieties of any particular language exist within communities. One entire recording session had to be redone due to the fact that the person, who had been selected to record one of the languages, had a particularly marked accent. This only became evident after the prototype was piloted amongst other native speakers. 
year students who were busy with their internship were also asked to share some anecdotes about their linguistic encounters which had led to misunderstanding. These personal accounts of their experiences of multilingual classrooms were animated and humorous, easing some of the tensions which had been anticipated. This orientation was able to enthuse an entire group - even students who were already fluent in several official languages and had expressed apprehension about the beginner level of the language section presenting them with little challenge.

The first three generic contact sessions are presented in the campus auditorium which seats 400 persons. This labour and time-saving decision implies one group taught in Afrikaans and a second group directly thereafter taught in English. Colleagues travelling from the main campus thus only need to do so once per week for a two-hour stint. The second session comprises a panel discussion by students representative of a variety of cultures, languages, and religions. After each participant's short, structured presentation, they take questions from the floor. Here too, ignorance, stereotyping, and pre-conceived ideas are dispelled by the authentic cultural exchange between peers. The third session introduces students to basic types of print and online dictionaries, as well as pronunciation and translation guides.

The remaining four language-specific sessions are offered simultaneously and here class size shrinks to more manageable groups of \pm 100 -150 students. Contact time is used for basic grammatical explanation and practise. Typical language learning strategies such as pair work, role play and at times, Behaviourist-type repetition are used while lecturers rely heavily on student co-operation and reflection. Very few hitches were encountered during this phase. An electronic classroom management system facilitated communication with the cohort while lecturers used e-mail to co-ordinate the pace and progress.

\section{Evaluate}

Since 2006 enrolments have averaged 640 students per annum with 874 students registered in 2011. By June 2011, 2,253 students had completed the module successfully. Annual class averages have ranged between 60,6 and $68,4 \%$ with a less than $5 \%$ repeat-rate. In a reiterative process, all aspects of the module are continually being assessed critically. Being a module with the political potential to highlight notions such as "us" and them", informal conversations with students and meetings with teaching staff have taken place regularly. In 2008, two years after implementation, an external evaluation panel comprising an international colleague, a local language teacher, a student focus group and an instructional designer made helpful suggestions.

The primary source of data has been a once-off electronic survey which students complete after their final exam $(\mathrm{N}=1036)$. Apart from 13 questions to obtain biographical detail related primarily to language proficiency, nine questions - of which eight are open-ended - pertain to the module content and facilitation. Annually \pm 200 students have responded anonymously, voluntarily, and in their own time. The response rate has been between $27-30 \%$ per annum. Qualitative data have been drawn from the open-ended survey questions as well as reflective essays written as part of the formative assessment strategies. As data sets were consistent across the 6-year period since implementation, data were collapsed and reported as a single unit. A reflective analysis of the design and development process adds coherence to the explanation. In 2011, second year students involved in the compulsory community engagement projects 
as well as fourth year students returning from a 6-month internship were asked to comment on the extent to which this module helped their interactions with learners. The responses of this group $(\mathrm{N}=356)$ were also recorded electronically. Figure 1 indicates to what extent these students felt that they would use their new found knowledge in their future work environment.

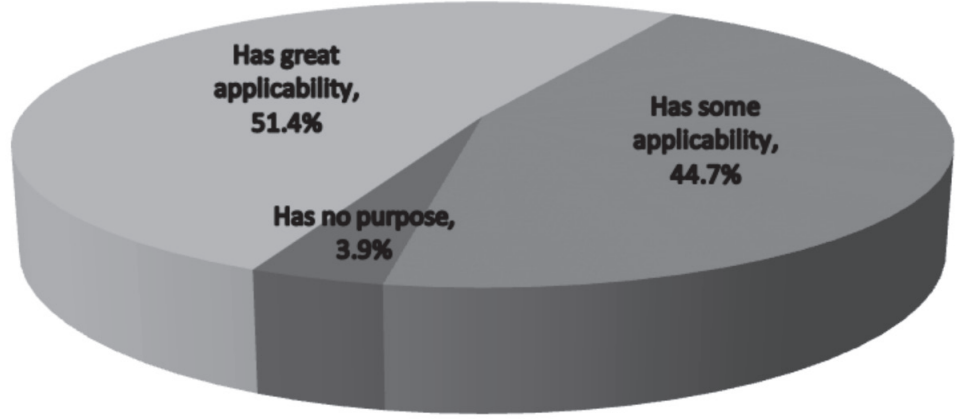

Figure 1: Usefulness of module content in future work environment

Since second year students have limited experience of the classroom realities encountered during the extended periods of teaching practice in their third and fourth years, a follow-up survey post-internship may provide a different view. It is also not known how many of these respondents were multilingual or perhaps intent on teaching in monoglot schools where the majority of learners shared a homogenous culture.

An analysis of qualitative data offered insight into the students' experiences and opinions of learning another language at this basic level. The response to a question relating to the module content was overwhelmingly positive with the vast majority of students clamouring for more periods, rightly arguing that increasing contact time would facilitate mastering more of the language. (Interaction in smaller groups and more practical sessions would be helpful," Respondent 136/2007; "The time given to this module is too short. I still want to learn more but thank you for a bright beginning of learning other languages," Respondent 17/2007; "It would be better to make it a semester", Respondent 21/2008; "Not enough time to master new languages. Make it a year and allow students to learn at least five languages", Respondent 113/2009; "Increase the course duration to two quarters at least ... I would love to have learnt more," Respondent 18/2009. Many were excited about the reactions of learners after being addressed in their mother tongue ("Speaking an African language to Africans while me being white. They were impressed by me!" Respondent 99/2009) while others remarked about the good rapport established amongst themselves ("The best thing about this module was we got to know our friends' languages and now we are willing to improve on that," Respondent 29/2009). Students feel more confident about communicating with persons whose mother tongue differs from theirs and students staying in halls of residence have in particular benefited from being able to practise their emerging vocabulary on peers. "Going out and meeting new and diverse people... Understanding that there are more challenges to pass through as an educator. This module helped me think outside the box and be proactive as a future educator," Respondent 88/2011). The following statements are unedited and in some cases translated extracts from open-ended questions which further amplify students' positive experiences: 
- "This module changed the way I think. I now look at other people with different cultures in a positive way." (Respondent 186/2007)

- The lecture on culture was an eye-opener for me and I am grateful for it." (Respondent $57 / 2008)$

- "I loved having a choice of languages to choose from." (Respondent4/2009)

- "I know basic words and instructions in another language... I feel more confident applying at a school with a multilingual student body." (Respondent 64/2010)

- "The fact that we got the opportunity to study a new language was quite fun and very interesting. I did not do very well but I passed!" (Respondent 73/2010)

- "To be stripped of my comfortable ideas about language and my future classroom." (Respondent 247/2011)

- "Understanding how important language is to a person's identity and learning how to accommodate differences.” (Respondent 348/2011)

Feedback regarding the usefulness of the learning support material has also been positive: "The CD was a user-friendly tool that brought the textbook to life! The authentic pronunciation is a helpful reference ... Smart idea!" Respondent 11/2007; "I really like the idea of having computer media to study from.” Respondent 81/2007. Many students preferred practising the pronunciation of the words and phrases after class at their own pace and in private albeit with the more traditional Audio-lingual drill-type method. However, some students complained about the $\mathrm{CD}$ not being operational while others struggled to navigate their way round the content - this seemed due to their own inadequate technological literacy rather than inherent technical faults. "I have not seen the CD because at home we do not have a TV" (Respondent 28/2009). Although respondents generally consider the textbook as "helpful", "useful", "clear and easy to understand", "accessible", "beneficial", "well structured", and "useful for future reference", containing "very informative" exercises. Some commented on the cost and the fact that it duplicated the word lists included on the $\mathrm{CD}$. The advantage of the pronunciation guide and audio clips have obviously been lost on them. Overall students are satisfied with the class presentations and all lecturers have been highly rated and considered knowledgeable, passionate, well prepared and supportive. ("I had the best lecturer! She made the lectures very interesting. I enjoyed studying Sepedi and think it will help me in my future career," Respondent 21/2010). Students found the course enlightening and applicable with $93.4 \%$ stating that their understanding of linguistic diversity has improved. Several students expressed the intention to enrol for an advanced language course.

Two recurring themes based on admissions made in many of the reflective essays are a) a definite attitude shift towards being more tolerant and sensitive towards difference ("It's not only that you get a "first-aid kit" on a specific language but it opened my eyes to see that we are truly a diverse country and that we need the basics of most cultures so that I do not offend my learners and that I do not feel offended by things they may do differently," Respondent 187/20011) and b) a new appreciation for students' own dominant language and the ease with which they communicate in it. The attempts of umlungus (White students) also produced appreciation ("The best about the module was ... hearing the white people trying to pronounce Zulu words. Wow! That was very nice, and I learned some new Zulu words too that I didn't know!" Respondent 50/2010). 
Currently the content and management of the module have been streamlined sufficiently but curriculum design is an on-going process. The main adaptation which will be implemented in 2013 is an increase of contact time and, by implication, credits. Management has decided to integrate this module into an existing one also related to literacy education. This not only doubles the contact time but also aligns well with the communication skills and voice hygiene - essential classroom literacies required by teachers. The section on dictionaries will be removed but included in the academic literacy preparation in the first year. An extension of language choice to include Braille and South African Sign Language should also address those multilingual speakers who are bored by the basic level of instruction and who become disruptive in class. We also intend to implement some form of peer support relying on mother tongue speakers to tutor and team teach. This pairing of proficient speakers with true beginners will also serve as an additional opportunity to gain teaching experience. The $\mathrm{CD}$ will undergo a third round of revision and will be updated in order to operate with ease on the most recent systems. Guidelines with regards to using the $\mathrm{CD}$ as a vital part of the module will be drafted to ensure that students do not rely solely on the textbook or consider the CD as a substitute. The practical links between this module and the service learning required by B Ed students will be strengthened and assessment will be structured to include use of an African language in authentic instructional contexts. Being granted a Pan-South African Language Board endorsement of the product may enhance the status of the course and assist in obtaining sponsorship to distribute this support tool nationally with the view to encouraging the extension of each teacher's language repertoire and their appreciation for diversity.

\section{Conclusion}

Teachers need more than an academic qualification to successfully negotiate the classroom space. Apart from instructional design skills, communicative skills, questioning skills, behavioural management and organisational strategies, they need an empathetic understanding of others, with particular reference to heterogeneity (Evans et al., 2009, Farr et al., 2005, Vandeyar and Jansen, 2008). This definitive module supports the additive approach to language learning as advocated by national policy (DoE, 1997) and has allayed initial apprehension especially in terms of students' favourable reaction to the content and colleagues facilitating the sessions. As more multicultural interaction takes place in society, we may have to reconsider the place of this module but currently it is having a positive impact on the confidence of student teachers who are able to demonstrate respect and goodwill towards learners by having acquired a better understanding of linguistic and cultural diversity and also extending their personal language profile with a functional knowledge of classroom vocabulary and instructional phrases in one of South Africa's official languages. Authentic contextualised language learning has been accomplished using a simulated environment, while electronic media afforded learning that is constructively aligned with the envisaged outcomes. This module could be replicated by other institutions involved in teacher education as it stands; the only adjustment required would be to include the regional vernacular(s) where applicable. The instructional design model is transferable to any other faculty/institution where dealing successfully with diversity and multilingualism is salient. The subject jargon and instructional context would need to be substituted. 
Upon reflection, as we now move into a second phase of development, it would be accurate to utter the Zulu idiom Imv'ibulal' indlovu ("The sheep has killed an elephant") since at the outset developing this new module seemed an impossible imperative to execute. In short, an intangible notion has finally come to fruition thanks to the input of many specialists.

\section{ACKNOWLEDGEMENTS}

This project was made possible by seed funding provided by the Department for Education Innovation (EI), University of Pretoria. The contributions of EI colleagues are highly appreciated. Their services in terms of project management, instructional and graphic design, video production and photography contributed significantly to the realisation of the $\mathrm{CD}$. Appreciation too, for colleagues in the Department of African Languages who assisted with materials development, accuracy checks of the text and audio clip recordings.

\section{REFERENCES}

Biggs, J. 1996. Enhancing teaching through constructive alignment. Higher Education 32(3): 347-364.

Biggs, J. \& Tang, C. 2007. Teaching for quality learning at university. Maidenhead: McGraw-Hill and Open University Press.

Bogaards, P. 2001. Lexical units and the learning of foreign language vocabulary. Studies in Second Language Acquisition 23:321-343.

Bogaards, P. \& Laufer-Dvorkin, B. 2004. Vocabulary in a second language: selection, acquisition, and testing. Amsterdam: John Benjamin's Publishing Company.

De Beer, J.J. \& de Beer, A. 2009. The four spaces model for improving work performance in a diverse team. Conference proceedings of the Performance Measurement Association, University of Otago, Dunedin, New Zealand 14-17 April 2009. Pp. 1-13. Retrieved from: http://www.pma.otago. ac.nz/pma-cd/papers/1096.pdf

Department of Education. 1997. Language in education policy. Retrieved from: http://www.education. gov.za/LinkClick.aspx?fileticket=XpJ7gz4rPT0\%3D\&tabid=390\&mid=1125

Department of Education. 2003. Revised National Curriculum Statement Grades R-9. Teachers' guide for the development of learning programmes. Languages. Pretoria: Department of Education.

Department of Basic Education. 2011. Minimum requirements for teacher education qualifications. Retrieved from: http://www.info.gov.za/view/DownloadFileAction?id=148017

Dick, W. \& Carey, L. 1978. The systematic design of instruction. Glenview, IL: Scott, Foresman.

Evans, R., Gauton, R., Kaschula, R., Prinsloo, D., Ramagoshi, R. \& Taljard, E. 2009. Classroom Literacies - understanding your multilingual classroom. Pretoria: Van Schaik Publishers.

Evans, R., and Cleghorn, A. 2010. "Look at the balloon blow up": Student teacher-talk in linguistically diverse Foundation Phase classrooms." South African Linguistics and Applied Language Studies 28(2): 141-151.

Farr, M., Seloni, L. \& Song, J. (eds). 2010. Ethnolinguistic diversity and education: language, literacy, and culture. New York: Routledge.

Fullan, M. 2006. Change theory - A force for school improvement. Centre for Strategic Education Seminar Series Paper No. 157. Retrieved from: http://www.michaelfullan.ca/Articles_06/06_ change_theory.pdf 
Hayles, V.R. \& Russel, A.M. 1997. The diversity directive: why some initiatives fail and what to do about it. New York: McGraw-Hill.

Horne, K.M. 1970. Optimum class size for intensive language instruction. The Modern Language Journal 54 (3).

Krieger, J. 2003. Class size reduction: implementation and solutions. ERIC Document Reproduction Service No. ED475489.

Kruse, K. 2000. Introduction to instructional design and the ADDIE model. Retrieved from: http://www.e-learningguru.com/articles/art2_1.htm [2007, June 18]

Jansen, J.D. 2009. Knowledge in the blood: confronting race and the apartheid past. Stanford: University Press.

Masombuka, S. 2011. Blade revives African languages. Sowetan, April 6, 2011. Retrieved from: http://www.sowetanlive.co.za/news/2011/04/06/blade-revives-african-languages

Morgan, L.Z. 2000. Class size and second-language instruction at the post-secondary level: a survey of the literature and a plea for further research. Italica 77(4) Linguistics and Pedagogy.

Morrison, J.L. \& Howell, S. 2007. Teaching one way and testing another: an interview with Scott Howell. Innovate, 3(3) Retrieved from: http://innovateonline.info/pdf/vol3_issue3/Teaching_One_ Way_and_Testing_Another-_An_Interview_with_Scott_Howell.pdf

Nan, C. 2005. Analysis of how to promote big class vocabulary teaching with multimedia and its application. Journal Of Anhui University Of Technology (Social Sciences) 22(4): 90-96.

Nation, P. 2001. Learning vocabulary in another language. Cambridge: Cambridge University Press.

Pettigrew, T. F. 2008. Future directions for intergroup contact theory and research. International Journal of Intercultural Relations 32:187-199.

Schmitt, N. (Ed.). 2010. An introduction to applied linguistics. (2nd ed.). London: Hodder Education.

South Africa. 2011. Minimum requirements for teacher education qualifications. Government Gazette 34467, July 15. Pretoria: Government Printer.

Street, B.V. 1984. Literacy in theory and practice. Cambridge: Cambridge University Press.

Thornbury, S. 2002. How to teach vocabulary. Harlow: Pearson Education.

Vandeyar, S. and Jansen, J.D., 2008. Diversity High: Class, Colour, Culture and Character at a South African high school. London: University Press of America.

Watson, R. October 1981. Instructional system development. In a paper presented to the International Congress for Individualized Instruction. ERIC Document Reproduction Service publication. No. ED209239

\title{
ABOUT THE AUTHOR
}

\section{Corresponding author: Dr Rinelle Evans}

Department of Humanities Education, University of Pretoria, Pretoria, South Africa PO Box 730, Wingate Park, Pretoria 0153, South Africa

Email: revans@postino.up.ac.za / Tel: 0124204272

\begin{abstract}
Short biographical notes on contributor: Rinelle Evans holds a doctorate in curriculum and instructional design with special reference to instructional communication via television technology. She is currently a senior lecturer involved with teacher education and facilitates modules related to literacies, communication skills and language teaching methodology in the Faculty of Education, University of Pretoria (South Africa). Her academic interests relate to English language teaching, instructional design and communication, assessment and bi-lingualism.
\end{abstract}

